\title{
Desenvolvimento e avaliação de um jogo multiplayer voltado à prática de atividades em sala de aula
}

\author{
Edwyn Batista ${ }^{1}$, André Maurício Cunha Campos ${ }^{2}$, \\ Alberto Signoretti ${ }^{3}$, Emerson Moura de Alencar ${ }^{1}$ \\ ${ }^{1}$ Instituto Metrópole Digital - UFRN, Natal-RN \\ ${ }^{2}$ Departamento de Informática e Matemática Aplicada - UFRN, Natal-RN \\ ${ }^{3}$ Departamento de Informática - UERN, Natal-RN \\ \{edwyn, emerson\} @imd.ufrn.br, andre@dimap.ufrn.br, albertosignoretti@uern.br
}

\begin{abstract}
Resumo. O presente trabalho apresenta uma estratégia para aproveitar os recursos digitais que alunos trazem às escolas (smartphones) para criar dinâmicas estimulantes para a realização de atividades em sala de aula. A estratégia é uma adaptação de dinâmicas de grupo e gincanas realizadas por professores durante aulas para motivar o estudo prévio de conteúdos, porém usando meios digitais para criar novas possibilidades de interação. Para tal, foi desenvolvido um jogo multiusuário, denominado "Desafio", que possui suporte a diferentes tipos de atividades interativas (quizzes, casamento chave-valor, entre outros). A mecânica do jogo segue a linha de jogos de gincana, onde os alunos são divididos em equipes e precisam colaborar entre si para fazer sua equipe vencer a adversária. Ao longo do jogo, os jogadores ganham itens que podem servir tanto para atrapalhar membros da equipe adversária, quanto para ajudar membros de sua equipe. A definição de itens competitivos e colaborativos ajudou a estabelecer um balanceamento adequado do jogo, permitindo que alunos com diferentes níveis de conhecimento no conteúdo possam aspirar em vencer o jogo. O jogo foi avaliado em turmas de disciplinas básicas de cursos de Tecnologia da Informação, apresentando resultados positivos no engajamento da atividade em sala de aula.
\end{abstract}

\begin{abstract}
This work presents a strategy to take advantage of digital resources brought to school by students (smartphones), aiming to create an exciting dynamics to carry out activities in the classroom. The strategy is an adaptation of group activities and competitions held by teachers during a lesson to stimulate the previous study of school programs, but using digital media, to create new possibilities for interaction. A multi-user game, called "Desafio", was developed for supporting different types of interactive activities (quizzes, matching, etc.). The mechanics of the game follows the line of gymkhana games, where students are divided into teams and need to work together to make their team win. Throughout the game, players earn items that can serve either to disrupt members of the opposing team or to help members of their own team. The definition of competitive and collaborative items helped to establish an adequate balance of the game, giving students at different levels of knowledge the hope of winning the game. The game was evaluated in groups of basic disciplines of the undergraduate course of Information Technology, with positive results on the engagement in the classroom activity.
\end{abstract}


V Congresso Brasileiro de Informática na Educação (CBIE 2016)

Anais do XXVII Simpósio Brasileiro de Informática na Educação (SBIE 2016)

\section{Introdução}

Nos últimos anos, um grande número de atividades digitais direcionadas ao processo de ensino/aprendizagem são jogos ou atividades lúdicas interativas (ex. [Buchinger and Hounsell 2015, Cascini and Campos 2015]). Educadores e pesquisadores têm percebido o ganho em trazer a diversão para a sala de aula, usando não apenas jogos criados com a finalidade exclusiva de auxiliar no processo de aprendizagem, como também jogos que foram pensados inicialmente apenas para o entretenimento, mas que possuem potencial para desenvolverem habilidades, transmitirem informação (mesmo que tangencialmente) e/ou despertarem curiosidade sobre um determinado tema a ser trabalhado em sala de aula. Esse misto de jogos educativos e de entretenimento aplicados em sala de aula tem reforçado a área de aprendizagem baseada em jogo [Felicia 2014], tema do trabalho apresentado no presente artigo.

No intuito de criar uma ferramenta que auxilie o professor a estimular os estudantes na realização de atividades de aprendizagem, foi desenvolvido um jogo digital capaz de promover a prática/treinamento de um conteúdo previamente exposto pelo professor. O jogo, denominado "Desafio", teve como objetivo principal possibilitar que os professores pudessem aproveitar os recursos digitais que os alunos trazem normalmente às escolas (smartphones) para criar uma dinâmica de grupo envolvente com seus alunos durante uma aula presencial. A expectativa é que a criação de uma dinâmica envolvente estimule a vontade do aluno em persistir aprendendo sobre o assunto e desenvolvendo suas habilidades. A dinâmica criada pelo jogo foi aplicada em três turmas de cursos relacionados à tecnologia da Universidade Federal do Rio Grande do Norte - UFRN, Brasil, e o engajamento dos alunos foi mensurado através de uma adaptação do instrumento EGameFlow [ $\mathrm{Fu}$ et al. 2009]. Os resultados mostraram o potencial positivo da ferramenta e da dinâmica criada em sala de aula pelo jogo.

\section{Trabalhos Relacionados}

Inúmeras iniciativas se propõem a inserir elementos motivacionais de jogos dentro de ambientes educacionais. Algumas procuram proporcionar novas experiências para os alunos nas atividades que já são amplamente utilizadas no seu cotidiano, como os exercícios acerca dos conteúdos estudados. Esses exercícios são transformados, com a ajuda de fatores oriundos dos jogos, a fim de ampliar o engajamento dos estudantes. É nesse contexto que se enquadra a proposta do jogo desenvolvido "Desafio". Ferramentas similares, que também exploram essas oportunidades, foram levantadas com o intuito de oferecer comparação entre as funcionalidades. Entre as mais difundidas estão Kahoot! [Wang 2015], Top Hat [Monocle 2016] e Quizlet [Vargas 2011]. Além do aspecto educacional, confrontamos aqui fatores considerados importantes à motivação, como competição e colaboração. Além dessas ferramentas, os jogos com fins de entretenimento com funcionalidade similares também foram avaliados, de forma a expor os atributos que proporcionam o engajamento. Os jogos avaliados possuem atividades semelhantes às atividades presentes no jogo Desafio, como questões de múltipla escolha. Assim traz-se o jogo "QuizUp" e o "Perguntados".

"Kahoot!" é um exemplo que se aproxima bastante do jogo "Desafio". Ele é classificado como um Sistema de Respostas de Alunos baseado em jogos (Game-based Student Response System) em [Wang 2015]. No Kahoot!, o professor faz o papel de 
mediador em um jogo de perguntas e respostas. Essas perguntas são projetadas na sala e os alunos submetem a resposta por seus dispositivos móveis. Há um tempo fixo para cada questão e, após seu término, a distribuição das respostas e o ranking dos 5 primeiros colocados é exibido na projeção. Nesse mesmo instante, individualmente, cada aluno pode ver, em seu dispositivo, o feedback de sua resposta e sua posição no ranking. Wang apresenta bons resultados do uso do Kahoot! e principalmente uma análise positiva sobre seu uso contínuo [Wang 2015]. No "Top Hat" há também apresentação de atividades em projeção para a turma e respostas dos alunos por seus dispositivos móveis. É possível criar competições baseadas em rankings e embates entre dois alunos. No Top Hat, os alunos podem submeter suas respostas por mensagem de texto, o que desobriga o uso de smartphones. O "Quizlet", por sua vez, é uma ferramenta de aprendizado baseada na Web. Ela se assemelha com o Desafio, além do caráter educacional, por empregar fatores de jogos em sua dinâmica. Os estudantes são submetidos à atividades como perguntas, flashcards e soletração como forma de introdução aos tópicos. Em seguida, têm a possibilidade de participar de uma corrida espacial baseada no acerto de rótulos de imagens e um jogo de correspondência entre figuras e significados. As atividades também apresentam feedback individual e dão chances ao jogador de consertar seu erro. Rankings são mantidos com a participação dos estudantes.

Dentre os jogos voltados exclusivamente ao entretenimento, o "QuizUp" é um jogo de quiz, onde um jogador convida outra pessoa para disputar uma partida. Eles escolhem um tema e ganha aquele que responder mais perguntas corretamente. Dentro do sistema, é possível manter relacionamento com outras pessoas, como seguidores ou seguidos. Essa funcionalidade é facilitada pela integração com as redes sociais. No jogo "Perguntados" também há disputa entre dois participantes. As respostas corretas a perguntas temáticas fazem com que se consiga insígnias. Quem conseguir um certo número de insígnias primeiro, sai vencedor. Ambos mantêm histórico de pontuação dos jogadores.

Pode-se evidenciar que o Desafio se diferencia das demais ferramentas principalmente pela interação que proporciona quando coloca os participantes em equipes. Assim, nesse contexto há também a existência de itens e a colaboração entre os participantes, fatores que são restritos ao Desafio e ao Perguntados. Esses aspectos podem beneficiar a interação entre os jogadores dentro de sala de aula, no caso do Desafio. O Perguntados, porém, não conta com possibilidade de configuração do conteúdo para aplicação. Ele tem a funcionalidade de criação de perguntas, porém elas são escolhidas aleatoriamente para a partida. Fatores como a projeção das atividades, intervalo entre a aplicação das atividades e embate entre dois participantes são fatores que não foram implementados no Desafio e que podem melhorar a experiência proporcionada aos jogadores. O Kahoot! e o Top Hat, por exemplo, dão a oportunidade ao professor revisar a atividade executada após o seu término, o que pode aprimorar o feedback dados aos alunos. Essa recaptulação só é permitida ao professor, no Desafio, após o término da partida, ou seja o conjunto de todas as atividades.

\section{O jogo Desafio}

O jogo Desafio se propõe a prover o incentivo ao exercício de atividades por parte dos alunos durante uma aula presencial. Para isso, o jogo se baseia em aplicar aos alunos de uma turma uma sequência de atividades (escolhidas pelo professor) a serem respondidas 
V Congresso Brasileiro de Informática na Educação (CBIE 2016)

Anais do XXVII Simpósio Brasileiro de Informática na Educação (SBIE 2016)

em seus dispositivos móveis durante a aula. Além disso, uma série de regras é imposta para que o sistema se assemelhe a um jogo para o aluno. Dentre essas regras, podemos citar os pontos por respostas corretas, que classificam os jogadores em um ranking. A execução do jogo se dá através de uma partida, onde todos os alunos (jogadores) de uma turma podem participar.

A cada atividade, o jogador deve escolher a resposta que julga ser correta. Então, caso acerte ou novas tentativas não sejam permitidas, segue para a próxima atividade. Se acertar a resposta, o jogador receberá os pontos devidos (De acordo com o número de tentativas realizadas. A cada resposta errada, se uma nova tentativa for aceita, a atividade valerá apenas a metade dos pontos que valiam na tentativa anterior). Quando o jogador acerta a resposta de maneira totalmente correta e na primeira tentativa, um item lhe será entregue. Após a última atividade do conjunto, mesmo que o tempo da partida não tenha se esgotado, o jogador será encaminhado à Tela Final e receberá os devidos pontos por tempo (proporcionais à relação entre o tempo restante da partida e seu tempo total).

Nessa tela, também são encontrados o ranking individual e a pontuação média das equipes, que podem ser modificados caso outros jogadores ainda estejam habilitados a responder. Ao término do tempo da partida, todos os jogadores, independentemente de terem finalizado ou não as atividades, são colocados na Tela Final. Dessa forma, o placar é consolidado e o resultado final é visualizado. A Figura 1 apresenta screenshots de diferentes tipos de atividades presentes no jogo (resposta objetiva e casamento de opções chave-valor), bem como a tela final de uma partida, onde a pontuação individual, o ranking e a equipe vencedora são apresentados.
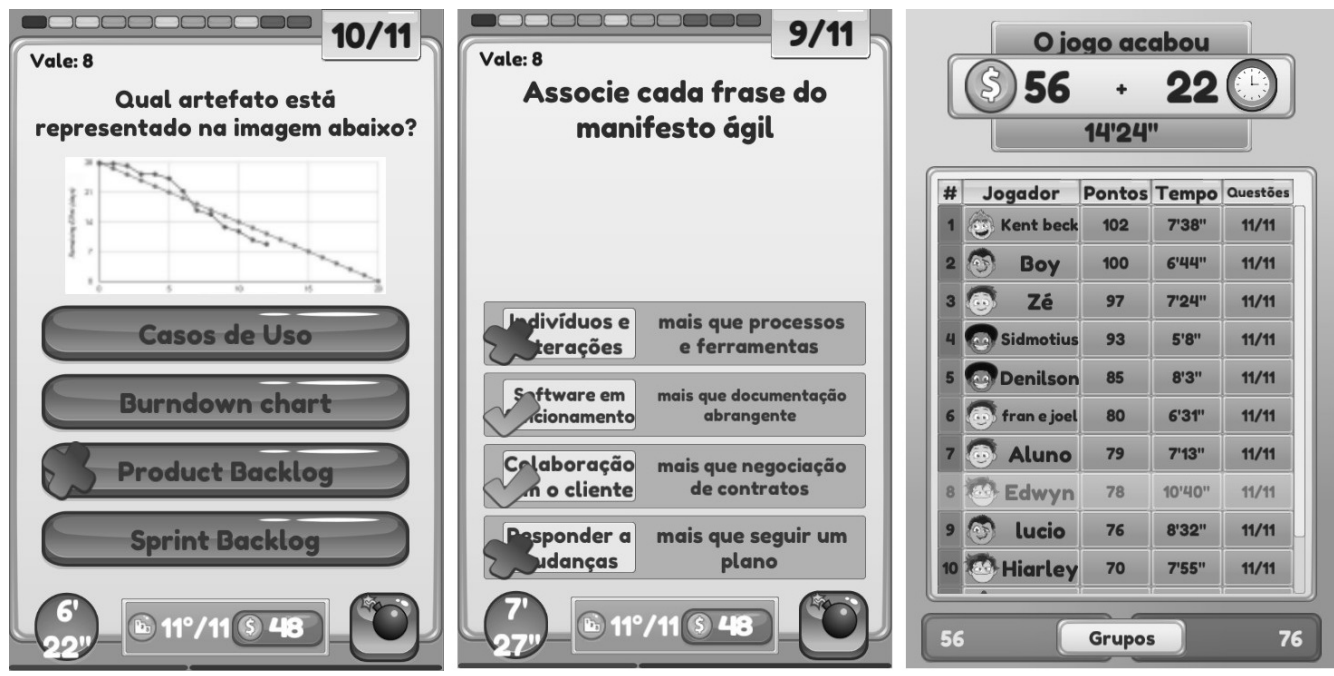

Figura 1. Telas de atividades e de conclusão da partida

O desenvolvimento do jogo Desafio procurou explorar e ampliar fatores como concentração, envolvimento emocional, colaboração e competição que podem impactar na relação dos alunos com as atividades. Esses componentes foram inseridos no jogo a fim de contribuir na ludificação do processo de ensino em sala de aula. Foram explorados aspectos motivacionais relacionados principalmente à interação social dos alunos no seio do jogo.

De fato, o ambiente educacional dentro de sala de aula conta com um fator de 
V Congresso Brasileiro de Informática na Educação (CBIE 2016)

Anais do XXVII Simpósio Brasileiro de Informática na Educação (SBIE 2016)

relevante importância para o aprendizado: a interação entre os alunos. Partindo desse princípio, o jogo Desafio tenta alcançar a interação entre os jogadores, tanto através de mecanismos de colaboração quanto de competição. A colaboração foi projetada para ocorrer entre membros de uma equipe e a competição entre membros de equipes adversárias.

No início da partida, os jogadores são separados pelo próprio jogo em duas equipes (por ordem de entrada na partida, os jogadores são colocados alternadamente nas equipes). Essa divisão é construída para fomentar o caráter colaborativo e competitivo entre os grupos. Durante toda a partida, as pontuações dos jogadores de uma equipe são levadas em consideração para calcular a média de pontos da equipe. Assim, a colaboração e competição são estimulados nas equipes, primariamente, pela pontuação dos seus participantes. A equipe com a melhor média é considerada vencedora. Apesar da competição por pontos entre as equipes não ser a principal provedora de engajamento dos alunos, é ela que fundamenta as demais interações, como abordaremos a seguir.
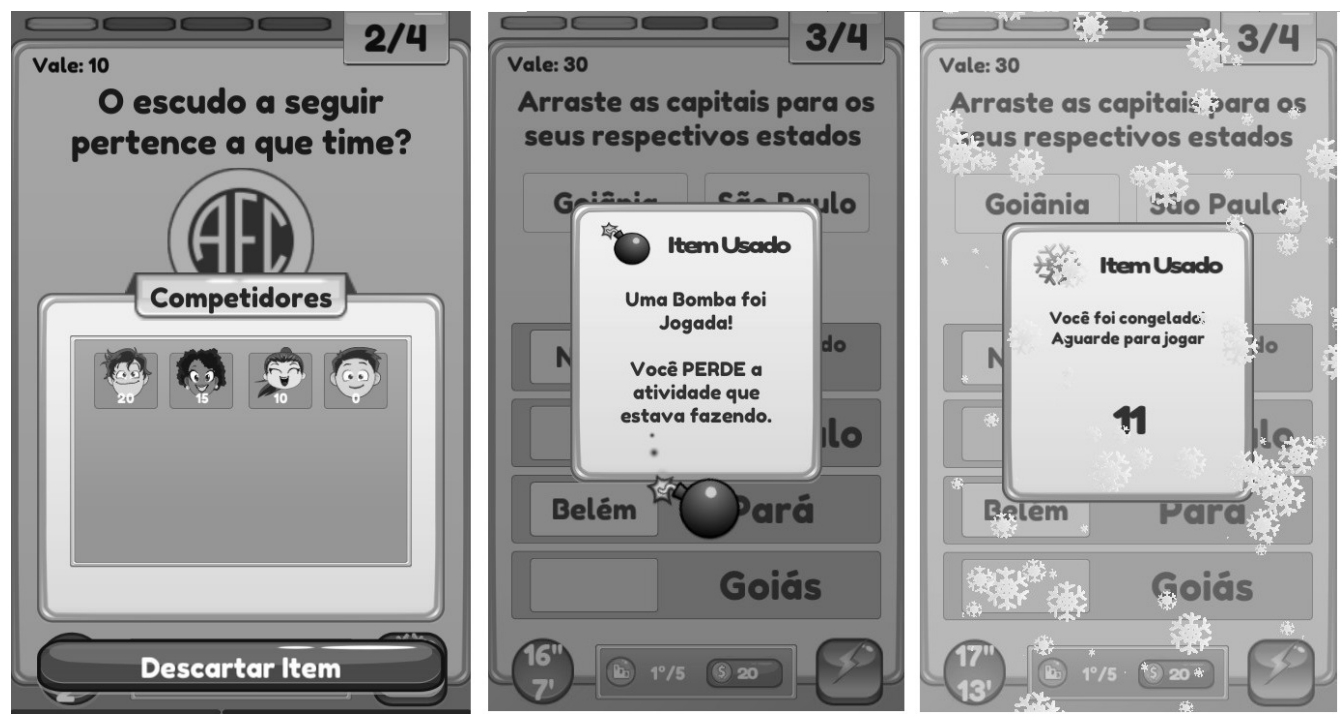

Figura 2. Tela inicial para criação do planejamento

Outro recurso empregado no jogo Desafio para estimular a interação entre os participantes é o uso de itens. Ao ganhar um item, o jogador pode selecionar um participante como alvo do efeito relacionado. Dessa mesma forma, ao ser atingido por um item, o jogo Desafio faz com que, de modo imediato, o jogador cumpra a punição ou benesse estipulada. Através desses itens, os jogadores podem alterar o fluxo do jogo dos demais participantes, sejam eles da mesma equipe ou não. A Figura 2 ilustra uma tela na qual o jogador seleciona o membro da equipe sobre o qual um item será aplicado. As duas telas seguintes ilustram o efeito de diferentes itens aplicados por outros jogadores sobre o jogador em questão.

Alterações definidas em cada item podem atrapalhar ou beneficiar os outros jogadores, por isso, implicam na pontuação dos demais. Assim, não apenas na competição individual, espera-se que os itens tenham capacidade de estimular o senso de participação em equipes, uma vez que são classificados em duas categorias:

1. Itens competitivos: essa categoria é composta por dois tipos de itens. Ela recebe 
V Congresso Brasileiro de Informática na Educação (CBIE 2016)

Anais do XXVII Simpósio Brasileiro de Informática na Educação (SBIE 2016)

esse nome pelo fato de ter sua aplicação voltada a prejudicar o andamento do jogo do adversário. Assim, o jogador só pode definir um participante da equipe oposta como alvo. Os itens são os seguintes:

(a) Bomba: quando um jogador é atingido por uma bomba, ele perde o direito de responder à atividade que está sendo apresentada a ele. Assim, o jogador não ganha pontos pela atividade e é direcionado para a próxima atividade da sequência. Caso a atividade corrente no momento da bomba seja a última da sequência, o jogador é encaminhado à Tela Final.

(b) Raio Congelante: o efeito desse item diz respeito ao atraso ocasionado ao jogador alvo. Ele inibe ações do jogador que foi atingido por um determinado tempo (25 segundos). Assim, ele não poderá responder à questões ou usar itens durante o período em que a punição do raio congelante estiver ativa. Nesse período, os botões presentes na tela são bloqueados.

2. Itens Colaborativos: também composta por dois itens, essa categoria tem como objetivo auxiliar o jogador alvo em seu desempenho no jogo. Desse modo, os alvos dos itens pertencentes a essa categoria são exclusivamente da mesma equipe do dono do item. Sendo assim, contam como ferramentas para a colaboração entre os participantes de uma equipe. Abaixo, descreve-se as características dos itens construtivos:

(a) Dica: é um item usado para prover ajuda ao jogador na resposta de uma atividade. Logo, quando o jogador é atingido por um item do tipo Dica, o Desafio, dependendo do Template da atividade corrente, fornece informações que facilitem a decisão a ser tomada. Para as atividades do tipo Múltipla Escolha, uma das opções erradas é desativada, demonstrando que ela não é a correta. Nas atividades de Casamento Chave-Valor, caso o jogador já tenha relacionado um ou mais pares erroneamente, um deles será corrigido; senão, um par que ainda não está relacionado é associado.

(b) Energia: o item de energia tem impacto na pontuação que é atribuída à atividade corrente. Dessa forma, quando atingido por um item do tipo Energia, é oferecida, ao jogador, a chance de, acertando a próxima resposta, receber o dobro dos pontos oferecidos normalmente pela atividade.

Os itens pregam papel importante também ao criar um mecanismo de participação mesmo dos jogadores/alunos que não estudaram previamente o conteúdo abordado no jogo. O objetivo é não deixá-los "de fora" da atividade, fazendo com que a atividade lúdica e a dinâmica criada na sala de aula possam estimulá-los a interagir e influenciar o resultado da sua equipe. Mesmo que eles não estejam entre os primeiros colocados, espera-se, com isso, que o aluno sinta-se motivado a continuar participando do jogo e cumprindo a missão do jogo, respondendo as atividades e aprendendo com os próprios erros.

\section{Avaliação da ferramenta}

\subsection{Metodologia}

O público alvo da avaliação foi restrito aos alunos do Ensino Superior da UFRN (Universidade Federal do Rio Grande do Norte) dos cursos de BTI (Bacharelado em Tecnologia da Informação) e Engenharia de Software. Três turmas foram disponibilizadas pelos professores e somam 28 alunos. Como instrumento de avaliação, foi utilizado uma adaptação 
V Congresso Brasileiro de Informática na Educação (CBIE 2016)

Anais do XXVII Simpósio Brasileiro de Informática na Educação (SBIE 2016)

do questionário de avaliação de engajamento e concentração em jogos educacionais EGameFlow [Fu et al. 2009].

A escala EGameFlow divide os fatores estudados em 8 categorias: Concentração; Clareza nos objetivos; Feedback; Desafios; Autonomia; Imersão; Interação Social; Melhoria do aprendizado. Os fatores do EGameFlow são transformados em um questionário que usa a Escala de Likert para obter os dados. Nesse questionário, as respostas têm 5 alternativas (Discordo Totalmente; Discordo Parcialmente; Estou Neutro; Concordo Parcialmente; e Concordo Totalmente) e os respondentes devem fazer a escolha de acordo com sua reação ao uso do jogo Desafio.

Em adição às questões do EGameFlow, foi igualmente introduzido uma avaliação sobre a aceitação de três importantes características do jogo: 1) o uso do dispositivo móvel em sala de aula; 2) o anonimato do jogador, e; 3) a personalização no jogo. Logo, três novas afirmações foram geradas para avaliar a percepção do jogador.

Por fim, em uma terceira parte da avaliação, foi realizada uma análise exploratória dos fatores motivacionais. Indica-se os elementos do jogo Desafio que buscam atribuir motivação e pediu-se que o jogador informasse se esse elemento foi capaz de produzir tal motivação. Novamente, utilizou-se a Escala de Likert, porém, agora, com alternativas diferentes: Muito Desmotivante; Desmotivante; Indiferente; Motivante; e Muito Motivante. Por fim, realizou-se um questionamento aos jogadores sobre a afinidade anterior com jogos e, como resumo da avaliação, o entendimento do jogador sobre a aplicabilidade do jogo Desafio em outras oportunidades. Um espaço para comentários, sugestões e críticas foi igualmente disponibilizado no final do questionário.

A execução do jogo Desafio ocorreu em três turmas, nos horários das respectivas aulas. Os professores foram orientados à construção das atividades e definição das variáveis que compõem a configuração da partida. Assim, o cadastro desses valores no sistema foi feito pela equipe do projeto. Esse procedimento produziu 3 conjuntos de atividades diferentes para as aulas. Os alunos foram orientados a fazer o download do jogo previamente. Uma explicação sobre a proposta do jogo e sobre seu funcionamento foi conduzida antes da partida ser iniciada. Houve também um período preliminar, onde os alunos puderam jogar sobre um conteúdo independente da disciplina da turma, com o objetivo dos alunos se acostumarem com o jogo. Por fim, a partida teve duração de 15 minutos, e, após sua conclusão, o questionário de reação foi submetido. A resposta aos questionários foi dada de modo anônimo.

\subsection{Resultados}

A análise dos dados foi feita pela média e desvio-padrão dos valores encontrados para cada categoria exposta pela adaptação do EGameFlow considerada no projeto. Tal método é observado em [Bjerkhaug et al. 2011, Fu et al. 2009]. Primeiramente, é necessário codificar as respostas com valores de -2 a 2 (Discordo Totalmente $=-2$ e Concordo Totalmente $=2$; Muito Desmotivante $=-2$ e Muito Motivante $=2$ ). Cada categoria é representada pela média e desvio-padrão das respostas dadas a afirmações que a compõem, considerando-se que se estabelecem categorias valoradas em uma escala equilibrada. Os resultados são expostos na Tabela 1 .

Os questionários indicam que o jogo Desafio, pela amostra de entrevistados descrita anteriormente, recebeu uma boa avaliação com relação aos fatores de aprendizado 
V Congresso Brasileiro de Informática na Educação (CBIE 2016)

Anais do XXVII Simpósio Brasileiro de Informática na Educação (SBIE 2016)

Tabela 1. Resultados obtidos por categoria

\begin{tabular}{l|c}
\hline Categoria & Média (DP) \\
\hline Concentração & $1,62(0,62)$ \\
\hline Feedback & $1,37(0,99)$ \\
\hline Desafios & $1,27(0,97)$ \\
\hline Autônomia & $1,18(1,06)$ \\
\hline Imersão & $1,56(0,78)$ \\
\hline Interação Social & $1,41(0,93)$ \\
\hline Melhoria do Aprendizado & $1,62(0,74)$ \\
\hline
\end{tabular}

Tabela 2. Valores para os questionamentos sobre dispositivos móveis, anonimato e personalização

\begin{tabular}{l|c}
\hline Afirmação & Média (DP) \\
\hline O uso do jogo no celular facilitou a dinâmica em sala de aula & $1,62(0,62)$ \\
\hline O anonimato durante as atividades facilitou a dinâmica em sala & $1,37(0,99)$ \\
\hline A escolha de um avatar melhorou a interação em sala & $1,27(0,97)$ \\
\hline
\end{tabular}

baseado em jogos. Isso impacta na boa recepção quanto aos aspectos motivacionais, e principalmente educacionais. A média superior a 1,25, na Tabela 2, em todos os quesitos, é um exemplo do impacto do jogo nos participantes. A discordância não ultrapassa $10 \%$ em qualquer avaliação. Dentre essas afirmações, entende-se que a categoria de Melhoria do aprendizado lida substancialmente com o objetivo principal do trabalho. A Média acima de 1,5 pontos, associada a mais de $90 \%$ de concordância podem ser considerados indícios do impacto do jogo Desafio na forma como os alunos veem as atividades e seus benefícios. Essa observação vale também para averiguar a intenção em aprofundar o conhecimento.

Todavia, é possível perceber um grau relativamente alto de reprovação nos aspectos de Feedback e Autônomia. Tal resultado pode ser atribuído à lentidão do software durante as execuções do Desafio. A discordância quanto ao quesito de Desafios e Interação social ressaltam a preocupação em ampliar a eficácia de tal fator no jogo. Os desafios estão bastante relacionados com o conteúdo das questões provido pelo professor. E provavelmente o jogo tenha que ser mais ativo nesse aspecto. Já a interação social recebeu muitos elogios, porém a principal crítica - nos comentários - veio com relação à necessidade de ampliação da colaboração.

As afirmações relativas ao uso de dispositivos móveis, anonimato e personalização são elencadas na Tabela 3.

O uso de celular e o anonimato apresentaram boa recepção. Entretanto, tanto pela observação das médias, quanto pela porcentagem, pode-se verificar um grau menor de aprovação, em comparação às demais afirmações, no quesito do uso de avatar para interação social. Assim, evidencia-se a necessidade em aprimorar o uso da personalização na dinâmica proporcionada. Uma alternativa é ampliar a importância do avatar no jogo. A correlação de Postos de Spearman apontou uma correlação positiva pequena $(0,17)$ entre o fato do anonimato ajudar a dinâmica e o uso do avatar melhorar a interação. Logo, podemos considerar que os fatores não estão correlacionados. 
V Congresso Brasileiro de Informática na Educação (CBIE 2016)

Anais do XXVII Simpósio Brasileiro de Informática na Educação (SBIE 2016)

Tabela 3. Resultados para os aspectos motivacionais

\begin{tabular}{l|c}
\hline O que motivou & Média (DP) \\
\hline Poder exercitar conteúdo da disciplina no formato de um jogo & $1,86(0,35)$ \\
\hline Poder ser ajudado por colegas de equipe & $1,25(0,58)$ \\
\hline Poder ajudar colegas de equipe & $1,43(0,50)$ \\
\hline Poder atrapalhar os oponentes & $1,39(0,78)$ \\
\hline Receber classificação individual no ranking de pontuação & $1,70(0,46)$ \\
\hline Receber classificação do grupo & $1,46(0,58)$ \\
\hline Possuir tempo limite para completar as atividades & $1,32(0,82)$ \\
\hline Possuir bonificação pela velocidade em completar as atividades & $1,53(0,64)$ \\
\hline O jogo possui diversificação na estrutura das atividades & $1,36(0,73)$ \\
\hline As atividades do jogo abordam conteúdos da disciplina & $1,82(0,39)$ \\
\hline
\end{tabular}

Os valores obtidos com a exploração da motivação foram positivos, já que contam com médias acima de 1 ponto e a quase inexistência de respostas do tipo "Desmotivante". Essa aprovação indica que a proposta motivacional do jogo Desafio teve êxito, produzindo uma dinâmica divertida e motivante em sala. Os aspectos de envolvimento dos temas estudados (Afirmação 25 e 34), a possibilidade de ajudar o companheiro de equipe (Afirmação 27) e a classificação individual (Afirmação 29) apresentaram resposta "Motivante" e "Muito Motivante" em todos os formulários.

As afirmações 28 (Poder atrapalhar os oponentes), 31 (Possuir tempo limite para completar as atividades) e 33 (O jogo possui diversificação na estrutura das atividades) obtiveram maior grau de indiferença e desmotivação, apontado também pelo desvio-padrão mais alto. Esse fato, valendo-se principalmente da não produção de desmotivação acentuda é capaz de indicar oportunidade de aperfeiçoamento para melhorar a motivação.

\section{Considerações finais}

O fato do jogo Desafio permitir, em sua configuração, a definição de atividades relacionadas aos assuntos estudados em sala de aula tem como objetivo estreitar a ligação entre os desafios enfrentados no jogo e aqueles encarados pelo jogador no seu dia a dia, nas aulas. Nesses aspectos, reside o principal objetivo do trabalho, voltado à motivação dos alunos em exercitar os assuntos estudados. Uma vez que são expostos a atividades e desafios dentro do jogo, pretende-se que os alunos superem as dificuldades enfrentadas e ganhem ferramentas, como a identificação de padrões de solução, que facilitem suas jornadas fora do jogo. É pretendido que, apesar de um possível insucesso no desenrolar do jogo, os jogadores entendam que habilidades são trabalhadas e que trazem benefícios em um momento subsequente, que compreendam a importância da experiência e que se motivem a continuar buscando o conhecimento exigido através do jogo.

É importante ressaltar que parte dos desafios e dificuldades é estipulada pelo professor na definição do conteúdo abordado pelas atividades do jogo. Por isso, orienta-se que o professor balanceie as exigências durante a sequência de atividades. De toda forma, o conjunto de conteúdos é direcionado ao tema explorado dentro de sala de aula. Essa importância se expande para todo o suporte que deve ser oferecido ao aluno em momento anterior e posterior ao jogo. O Desafio se coloca apenas como uma ferramenta para auxiliar o professor em seu processo de ensino. 
V Congresso Brasileiro de Informática na Educação (CBIE 2016)

Anais do XXVII Simpósio Brasileiro de Informática na Educação (SBIE 2016)

Os resultados obtidos pela avaliação da reação dos estudantes foram positivos. Isso representa a satisfação dos objetivos do trabalho. Primeiramente, o questionário com afirmações baseadas no EGameFlow apresentou indícios de eficácia no engajamento dos alunos. Isso concorda com o objetivo relativo ao game-based learning e a motivação em continuar aprendendo. Já a parte exploratória de recursos motivacionais foi capaz de apresentar o sucesso dos elementos de motivação do jogo Desafio, validando assim o objetivo que diz respeito à construção de dinâmica diferenciada dentro de sala.

Sugestões levantadas pelos estudantes devem ser consideradas em trabalhos futuros. Essas sugestões criativas dão conta de alternativas na dinâmica do jogo, criação de novos itens, design participativo, entre outros; Correções na implementação devem ser feitas para melhorar a velocidade de resposta do sistema; E o efeito da utilização continuada também deve ser objeto de análise: esse estudo deve servir para observar o impacto do jogo a longo prazo e verificar se as respostas dadas aos formulários de reação não possuíram caráter momentâneo dada a influência do envolvimento emocional proporcionado pelo jogo. Tal avaliação servirá para fortificar a validação do projeto e, associada a experimentação, consolidar uma metodologia de aplicação que torne o jogo Desafio ainda mais eficaz.

\section{Referências}

Bjerkhaug, S. W., Mathisen, R. O., and Valtola, L. A. (2011). The Amazing City Game. 301 .

Buchinger, D. and Hounsell, M. (2015). O Aprendizado através de um Jogo ColaborativoCompetitivo contra Dengue. In Anais do XXVI Simpósio Brasileiro de Informática na Educação, SBIE 2015, pages 439-448.

Cascini, D. and Campos, S. (2015). Avaliação de Jogos Educacionais Multiusuários: Uma Revisão Sistemática da Literatura. In Anais do XXVI Simpósio Brasileiro de Informática na Educação, SBIE 2015, pages 519-528.

Felicia, P. (2014). Game-based Learning: Challenges and Opportunities. Cambridge Scholars Publishing, Newcastle upon Tyne, 1st unabridged edition edition.

Fu, F.-L., Su, R.-C., and Yu, S.-C. (2009). EGameFlow: A scale to measure learners' enjoyment of e-learning games. Computers \& Education, 52(1):101-112.

Monocle, T. H. (2016). Top hat: Interactive Teaching Platform. Disponível em https://tophat.com/. Último acesso: 10/06/2016.

Vargas, J. M. (2011). Modern learning: Quizlet in the social studies classroom. Thesis, Wichita State University.

Wang, A. I. (2015). The wear out effect of a game-based student response system. Computers \& Education, 82:217-227. 